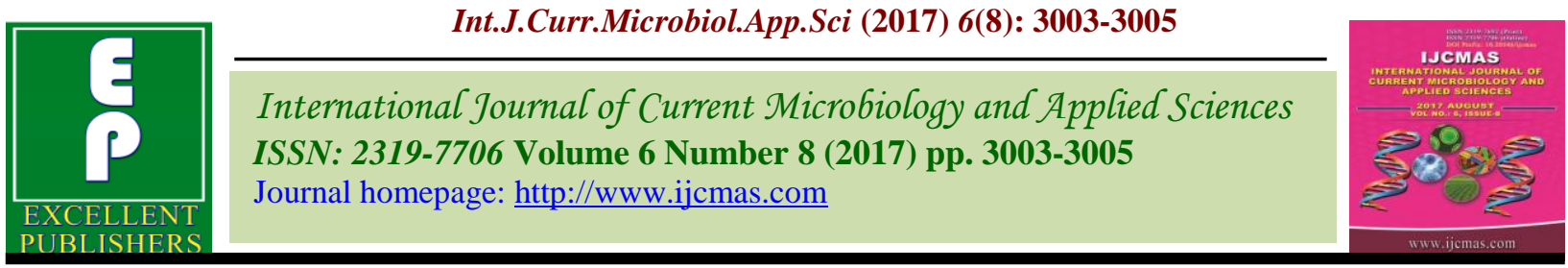

Original Research Article https://doi.org/10.20546/ijcmas.2017.608.359

\title{
Sero Prevalence of HIV among General Population Attending a Tertiary Care Hospital in Telangana, India
}

\author{
R. Shyamala ${ }^{*}$, K. Vijaya ${ }^{2}$ and D. Achut Rao ${ }^{1}$ \\ ${ }^{1}$ Department of Microbiology, ${ }^{2}$ Department of Pathology, Mallareddy Medical College for \\ Women, Hyderabad, Telangana, India \\ *Corresponding author
}

\section{A B S T R A C T}

Keywords

Seroprevalence, HIV, Screening.

Article Info

Accepted:

23 June 2017

Available Online:

10 August 2017
In India the first HIV case was detected in 1986, and since then it has been reported from all states and union territories. This is a retrospective study to know the seroprevalence of HIV among patients in a tertiary care hospital. This is a study included 2457 patients who attended Mallareddy Medical College for Women's Hospital, from January 2016 to December 2016. A total of 2457 patients were tested and out of which 38 were seropositive for HIV, with a prevalence rate of $1.5 \%$. Out of these 38 cases 21 were males, and 17 were females (M: F- 1: 0.8). It is essential to strength then all testing protocols to include referral of HIV positive clients to well established treatment, care and support facilities.

\section{Introduction}

In 1983 Lucmontegniere and colleagues from Pasteur Institute, Paris isolated a Retrovirus from a West African patient with persistent generalised lymphadenopathy which is a manifestation of AIDS. (Ananthnarayan). In India the first HIV case was detected in 1986, and since then it has been reported from all states and union territories. According to National Aids Control Organization (NACO) the national adult HIV prevalence in India is $0.36 \%$ (Harsha Kumar). Six Indian states with high HIV and AIDS prevalence are Manipur (1.4\%). Andhra Pradesh (0.90\%), Mizoram $(0.81 \%) \quad$ Nagaland $(0.78 \%)$, Karnataka $(0.63 \%)$ and Maharashtra $(0.55 \%)$. Prevalence of HIV infection among pregnant women in India is reducing. In 1986 the Government of
India established a National Aids Control Committee under the Ministry of Health and Family Welfare to formulate a strategy for dealing with HIV AIDS prevalence. [UNAIDS]. The prevalence of AIDS in India has declined in $2015(0.26 \%)$ as compared to 2001-2003 (0.38\%) [NACO, 2016]. The National AIDS Control Programme (NACP) started in 1990 lays maximum emphasis on the widespread reach of information, education and communication on HIV/AIDS prevention (Laghave et al., 2015).

\section{Materials and Methods}

This is a retrospective hospital based study which included 2457 patients who attended 
MRMCW Hospital from January 2016 to December 2016. Blood samples were collected after pretest counseling and informed consent. The samples were tested for HIV antibodies as per NACO guidelines.

The first antibody test done was ELISA. If the initial result was positive, it was confirmed using two other supplemental tests. After HIV test results were known posttest counseling was done and the results were declared. Confidentiality of the data was maintained.

\section{Results and Discussion}

A total of 2457 patients were tested and out of which 38 were seropositive for HIV, with a prevalence rate of $1.54 \%$. Out of these 38 cases 21 were males, and 17 were females (M: F- 1:0.8). In India 90\% of the reported cases of HIV are aged between 15 and 40 years and belong to low socioeconomic groups (Monica Malta et al.,)). It is concentrated among vulnerable population which include people who have unprotected sex with sex workers and those who inject drugs with contaminated needles. In rural areas women account for increasing rate of HIV infection. (S. Solomon et al.,) the low rate of multiple partner concurrent sexual relationships seems to have protected the larger body of people so far.

India has about 2.1 million people living with HIV, the third largest on the planet after South Africa and Nigeria according to UNAIDS report 2013. According to National Aids Control Organization (NACO) the National adult HIV prevalence in India is $0.36 \%$. The states with high HIV prevalence rates include Manipur (1.40\%), Andhra Pradesh (0.90\%), Mizoram (0.81\%), Nagaland $(0.78 \%)$, Karnataka $(0.63 \%)$ and Maharashtra $(0.55 \%)$.

In 1986,the first known case of HIV was diagnosed by Dr. Suniti Solomon, and her student, Dr. Selappan Nirmala amongst female sex workers in Chennai, Tamil Nadu. [Sternberg et al.,], [Pandey, et al.,] It is essential to strength then all testing protocols to include referral of HIV positive clients to well established treatment, care and support facilities.

Fig.1 Pie diagram to show the seroprevalence of HIV at our hospital

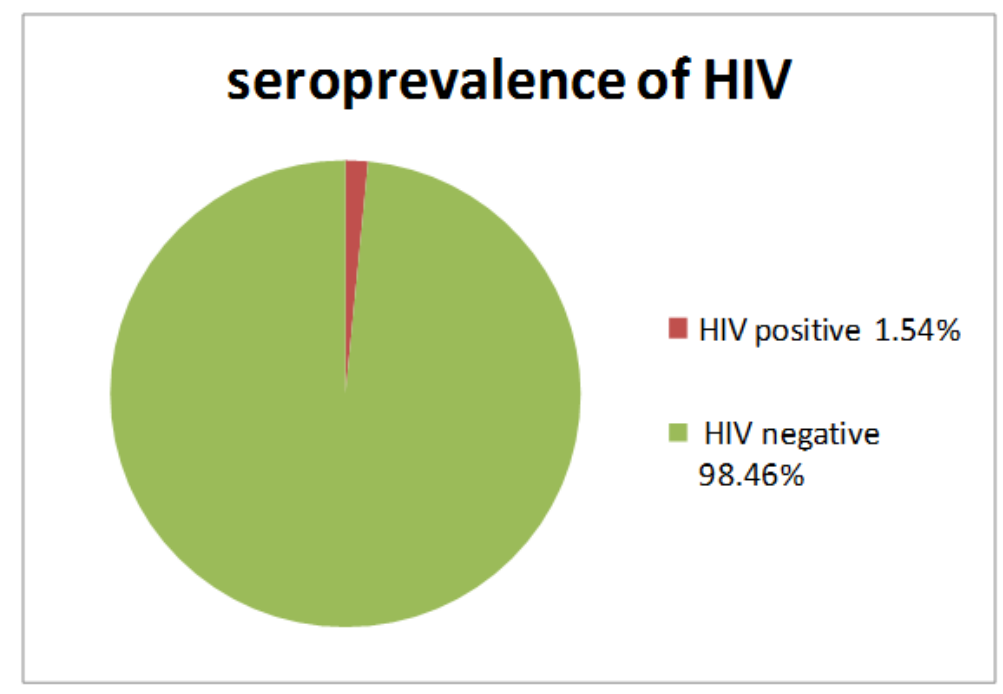

Few hospitals and physicians provide health care for people living with HIV/AIDS, partly because of reluctance among health care personnel to deliver treatment to this 
population. The reasons for this reluctance include personal values and prejudices, and inaccurate perception of occupational risk entailed in health care, and the belief that HIV negative patients will refuse to share heath care facilities with people living with HIV.

In our study the seroprevalence of HIV is $1.5 \%$. Identifying the high risk group of people in the population and counseling and testing the patients' helps in proper treatment. Highly Active Anti-Retro Viral Therapy (HAART) is started in India based on WHO criteria: absolute CD4 count $<200$ cells/ microliter, patient has an AIDS defining illness or CD4 200 - 350 with opportunistic infections.

Programmes that provide services need to be implemented on public health services throughout the country, in order to decrease the vulnerability of the populations to HIV infection. The study of seroprevalence of HIV helps to formulate preventive steps in reducing the incidence of HIV infection. Developing many appropriate policies and educating people about HIV, promoting safe behaviour, counseling and creating more awareness among individuals in the community should be done.

\section{References}

Ananthnarayan and Panicker's, a text book of Microbiology Universities Press $8^{\text {th }}$ Edition pg-569.

Harsha Kumar. H.N., et al., Open Medicine 2009; 3(1): e 26-e30.

Laghawe, A., Faujdar, S.S. 2015. Declining Trends in HIV Prevalence: A Tertiary Care hospital based 05 Years Retrospective Analysis. 4(6): 927-36

Monica Malta.et al., BMC Public Health, 2010, 10:317.

Pandey, Geeta 2016-08-30. "The woman who discovered India's first HIV cases". BBC News. Retrieved 2016-12-08.

Solomon S., et al., Postgraduate Medical Journal, 2006, September; 82(971): 545-547.

Sternberg, Steve 23 February 2005. HIV scars India USA Today.

UNAIDS, AID Epidemic update. December 2004.

\section{How to cite this article:}

Shyamala, R., K. Vijaya and Achut Rao, D. 2017. Sero Prevalence of HIV among General Population Attending a Tertiary Care Hospital in Telangana, India. Int.J.Curr.Microbiol.App.Sci. 6(8): 3003-3005. doi: https://doi.org/10.20546/ijcmas.2017.608.359 